\title{
Unusual Finding of Vertebral Artery Fenestration in Spontaneous Deep Nuclear Hemorrhage
}

\author{
Karuna Tamrakar ${ }^{1}$, Binod Bhattarai ${ }^{1}$, Sunil Munakomi ${ }^{2}$, Pramod Chaudhary ${ }^{3}$

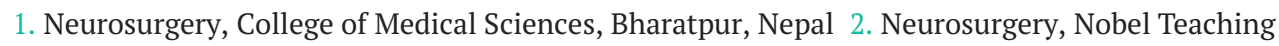 \\ Hospital, Nepal 3. General Surgery, Nobel Medical College
}

$\square$ Corresponding author: Karuna Tamrakar, tamrakarkaruna@gmail.com Disclosures can be found in Additional Information at the end of the article

\section{Abstract}

Vertebral artery fenestration is accidentally detected during angiography or autopsy. Spontaneous deep nuclear hemorrhage in association with vertebral artery fenestration is a very unusual finding in angiography. Such an unusual finding has not been reported in the English literature. Here, we report two cases of spontaneous deep nuclear hemorrhage that presented with features of raised intracranial pressure. Computed tomography revealed a deep nuclear acute bleed in both cases. Digital subtraction angiographic findings were normal other than the presence of a long segment vertebral artery fenestration. Both extracranial and intracranial variations were detected. Although the existence of vascular fenestration in the vertebrobasilar system produces less clinical importance, it may influence the management of cervical and intracranial pathologies to avoid iatrogenic injury.

Categories: Neurosurgery

Keywords: spontaneous deep nuclear hemorrhage, extracranial, intracranial, vertebral artery fenestration

\section{Introduction}

There are many distinctions in the origin and course of the vertebral artery (VA). This anatomical variation usually affects the surgical procedure. Approximately $1-2 \%$ of vertebral artery fenestrations have been accidentally detected at autopsy or on cerebral angiography [1]. Among the 75 cases reported by Hasegawa, et al., 69\% were located at the extracranial segment of the VA. Only 20 cases had fenestration at the intracranial segment [2]. Whilst reports on the detection of extracranial fenestration are more frequent than the intracranial segmentation of the VA, both types of fenestration were demonstrated in each of our reported cases [3].

Received 09/13/2015 Review began 09/22/2015 Review ended 11/24/2015 Published 01/06/2016

C) Copyright 2016

Tamrakar et al. This is an open access article distributed under the terms of the Creative Commons Attribution License CC-BY 3.0., which permits unrestricted use, distribution, and reproduction in any medium, provided the original author and source are credited.
Aneurysmal growth from the fenestrated VA is extremely rare. Additionally, arteriovenous malformation has been explicated in the English literature in association with VA fenestration [4]. However, no report has been specified so far regarding the angiographic detection of a fenestrated VA in a deep nuclear bleed.

\section{Case Presentation}

Informed patient consent was obtained from both patients described in this report. No identifying patient information is present in this paper.

\section{Case 1}




\section{Cureus}

A 35-year-old hypertensive lady presented with the sudden onset of a severe headache, complicated by several episodes of vomiting, and an altered level of consciousness. On examination, the systemic blood pressure (BP) was 220/140 mm of $\mathrm{Hg}$ with a Glasgow Coma Scale (GCS) of E3, V4, and M6. Her speech was slurred with right-sided upper motor neuron facial palsy, left hemiparesis of grade $3 / 5$ in the lower extremity, and $2 / 5$ in the upper extremity was present. A CT scan showed a $4.8 \times 1.9 \mathrm{~cm}$ right putaminal bleed (Figure $1 \mathrm{~A}$ ). Extracranial VA fenestration at the level of $\mathrm{C} 1$ and $\mathrm{C} 2$ was demonstrated on left VA injection (Figure $1 A-1 B$ ). Before entering the skull, two limbs of fenestrated VA united to become a normal terminal segment.

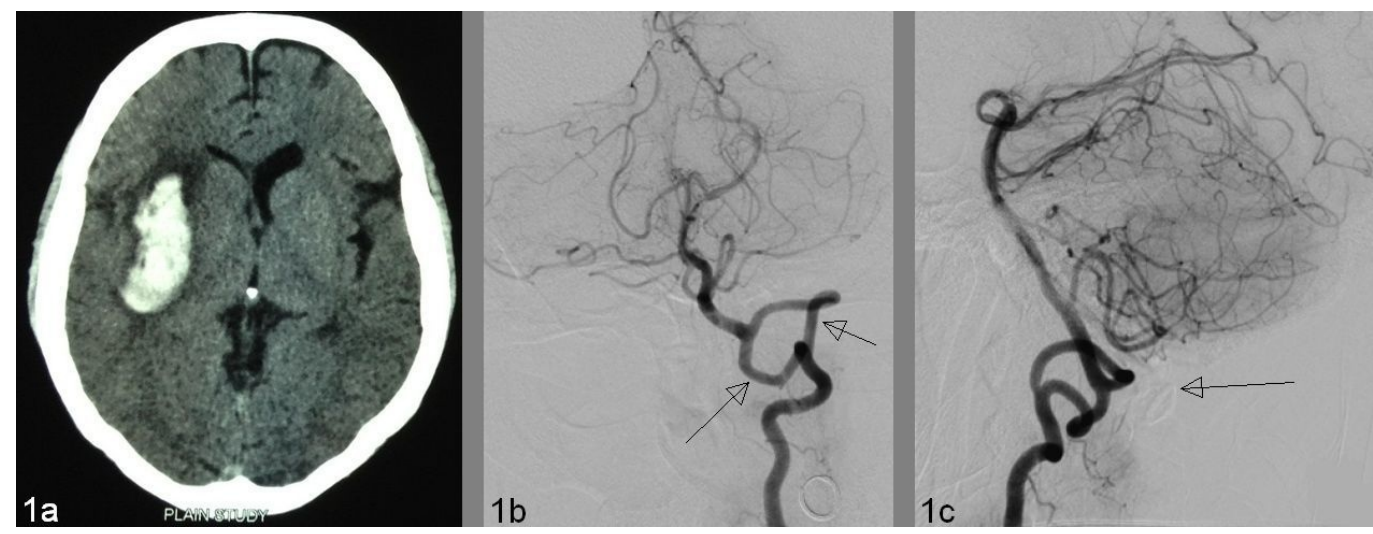

FIGURE 1: Extracranial vertebral artery fenestration in a 35year-old hypertensive lady who presented with a right putamen hemorrhage

1A: Acute right putamen hemorrhage in CT scan. 1B: Detection of both widely placed fenestrated segments of VA (arrows) in selective left VA injection (AP view). Length/width of the right limb is $58.7 \mathrm{~mm} / 3.1 \mathrm{~mm}$ and the left limb is $62.3 \mathrm{~mm} / 2.9 \mathrm{~mm}$. VA diameters distal to fenestration are $4.0 \mathrm{~mm}$ and proximal is $4.3 \mathrm{~mm}$. 1C: Bony landmark of the C1 vertebra (long arrow) in lateral view.

\section{Case 2}

A 54-year-old non-hypertensive man presented with a history of the sudden onset of weakness of the right-sided extremities, complicated by headache and nausea. On examination, his BP was 180/110 mm of Hg. GCS was E4, V4, and M6 with right-sided hemiparesis of power grade $1 / 5$. A plain CT scan detected a $2.8 \times 2.4 \mathrm{~cm}$ acute bleed in the right thalamus and posterior limb of the internal capsule (Figure $2 A$ ). On digital subtraction angiogram (DSA), VA fenestration was demonstrated in the selective left vertebral angiography (Figure $2 B-2 C$ ). 


\section{Cureus}


\section{FIGURE 2: Intracranial vertebral artery fenestration in a 54- year-old man with a right thalamic bleed}

2A: Plain CT scan shows a right thalamic bleed. 2B: VA fenestration involving both intracranial (arrowhead) and extracranial segments in lateral view on selective left VA angiography, the long arrow indicating the bony impression of the posterior arch of the $\mathrm{C} 1$ vertebra. $2 \mathrm{C}$ : Oblique view of VA fenestration (arrowhead). Length/width of the right limb is $20.7 \mathrm{~mm} / 2.2 \mathrm{~mm}$ and of the left limb is $33.5 \mathrm{~mm} / 3.1 \mathrm{~mm}$. VA diameters distal to fenestration is $3.4 \mathrm{~mm}$ and proximal measurement is $3.9 \mathrm{~mm}$.

\section{Discussion}

Fenestrations, duplications, hypoplasias, aplasias, and fetal persistence are the different anatomical variations of the cerebral arteries. The origin is always single in fenestration. Duplication means a division of an artery throughout its course, starting from its origin [5]. Fusion of the duplicated artery has also been explained in the literature. Additional terms have been coined for the fenestration as segmental duplication and for duplication as extreme fenestration [6]. When an embryo develops into the 7-12 mm stage, the VA appears from an anastomosis between the cervical intersegmental arteries in each side. During this stage, when a transient lateral basilar-vertebral anastomosis persists, fenestration of the intracranial portion of the VA results [7]. Lasjaunias, et al., however, elucidated that there are two types of fenestration: an arterial split and true duplication, thereby using fenestration as a generic description of any situation in which there is a double segment of the vertebral artery [8]. Hence, it has been considered as a congenital abnormality rather than being of pathological significance. There are several publications regarding fenestration of the vertebral artery coexisting with cerebral aneurysms [9]. In congenital vascular anomalies like vascular duplications, fenestrations are very frequently associated with other malformations, particularly with cerebral aneurysms and arteriovenous malformations, although corpus callosum agenesis, cervical intervertebral synostosis, multiple block vertebra with partial hemivertebra and severe cervical scoliosis, trigeminal neuralgia, epidermoid cysts, and persistent primitive trigeminal artery have been reported in association with vertebral artery duplication or fenestration [1, 10-12]. However, there has not been any reported case of spontaneous deep nuclear bleed in association with vertebral artery fenestration. Fenestrations of the extracranial course of the vertebral arteries are rare and are usually noted incidentally during angiographic studies or post-mortem examinations [13]. Several theories have been implicated for the development of the fenestration in the intracranial vasculature. Arterial dissection and a thromboembolic event could have been the causes for the basal ganglia bleed that has been majorly supplied by middle cerebral artery perforators [14]. Since the hemodynamic effect in the majority of the developmental vascular anomalies gives rise to the growth of an aneurysm, there is no such clarification to explain the basal ganglia bleed and the 
fenestrated vertebral artery. It has been stated that vertebral artery duplications or fenestrations were incidental findings with no significant pathologic and clinical consequences.

\section{Conclusions}

Vertebral artery fenestration per se may not predispose to significant vascular consequences. Other than vascular dissection, it can only be the pathogenesis for the development of local vascular disease. The kinking or compressive effect at the origin of fenestration may produce dizziness; however, angiographic detection of vertebral artery fenestration in spontaneous deep nuclear bleed is very rare. Although the existence of vascular fenestration in the vertebrobasilar system produces less surgical importance, it may influence the management of intracranial and cervical pathologies to avoid iatrogenic injury to the vertebral artery.

\section{Additional Information Disclosures}

Human subjects: Consent was obtained by all participants in this study. Conflicts of interest: In compliance with the ICMJE uniform disclosure form, all authors declare the following: Payment/services info: All authors have declared that no financial support was received from any organization for the submitted work. Financial relationships: All authors have declared that they have no financial relationships at present or within the previous three years with any organizations that might have an interest in the submitted work. Other relationships: All authors have declared that there are no other relationships or activities that could appear to have influenced the submitted work.

\section{References}

1. Rieger P, Huber G: Fenestration and duplicate origin of the left vertebral artery in angiography. Report of three cases. Neuroradiology. 1983, 25:45-50. 10.1007/BF00327480

2. Hasegawa T, Ito H, Hwang WZ, Yamamoto S: Single extracranial-intracranial duplication of the vertebral artery. Surg Neurol. 1986, 25:369-72. 10.1016/0090-3019(86)90212-0

3. Drapkin AJ: The double lumen: a pathognomonic angiographic sign of arterial dissection? . Neuroradiology. 2000, 42:203-205. 10.1007/s002340050046

4. Uchino A, Kato A, Abe M, Kudo S: Association of cerebral arteriovenous malformation with cerebral arterial fenestration. Eur Radiol. 2001, 11:493-96. 10.1007/s003300000640

5. Pleş H, Loukas M, Iacob N, Andall NR, Miclăuş GD, Tubbs RS, Matusz P: Duplication of the distal end of the left vertebral artery with fenestration of the right posterior cerebral artery. Rom J Morphol Embryol. 2015, 56:575-77.

6. Polguj M, Podgórski M, Jędrzejewski K, Topol M, Majos A: Fenestration and duplication of the vertebral artery: the anatomical and clinical points of view. Clin Anat. 2013, 26:933-43. 10.1002/ca.22231

7. Padget DH: The development of the cranial arteries in the human embryo . Contr Embryol. 1948, 32:205-61.

8. Lasjaunias P, Braun JP, Hasso AN, Moret J, Manelfe C: True and false fenestration of the vertebral artery (Article in English, French). J Neuroradiol. 1980, 7:157-66.

9. Sanders WP, Sorek PA, Mehta BA: Fenestration of intracranial arteries with special attention to associated aneurysms and other anomalies. AJNR Am J Neuroradiol. 1993, 14:675-80.

10. Handa J, Teraura T, Imai T, Handa H: Agenesis of corpus callosum associated with multiple developmental anomalies of the cerebral arteries. Radiology. 1969, 92:1301-4. 10.1148/92.6.1301

11. Kubo M, Hacein-Bey L, Varelas PN, Ulmer JL, Lemke DM, Cusick JF: Ruptured saccular aneurysm of distal vertebral artery fenestration managed with Guglielmi detachable coils and intraventricular tissue plasminogen activator. Surg Neurol. 2005, 63:244-48. 10.1016/j.surneu.2004.02.038

12. Uchino A, Sawada A, Takase Y, Kudo S: Extreme fenestration of the right vertebral artery: 


\section{Cureus}

magnetic resonance angiographic demonstration. Eur Radiol. 2002, 12:S32-S34.

13. Sim E, Vaccaro AR, Berzlanovich A, Thaler H, Ullrich CG: Fenestration of the extracranial vertebral artery: review of the literature. Spine (Phila Pa 1976). 2001, 26:E139-42.

10.1097/00007632-200103150-00007

14. de Andrade GC, de Oliveira JG, Dauar RF, Nalli DR, Braga FM: Dissecting aneurysm of the intracranial fenestrated vertebral artery submitted to endovascular treatment: case report (Article in Portuguese). Arq Neuropsiquiatr. 2005, 63:352-56. 10.1590/S0004-

282X2005000200031 